\title{
Antimicrobial action of chlorhexidine digluconate in self-ligating and conventional metal brackets infected with Streptococcus mutans biofilm
}

This article was published in the following Dove Press journal:

Clinical, Cosmetic and Investigational Dentistry

\author{
Ana Paula Dias \\ Marco Aurélio Benini \\ Paschoal \\ Rafael Soares Diniz \\ Lucas Meneses Lage \\ Letícia Machado Gonçalves \\ Department of Dentistry, CEUMA \\ University, São Luis, Maranhão, Brazil
}

Correspondence: Letícia Machado Gonçalves

Department of Dentistry, CEUMA University, Rua Josué Montelo, Number I, Renascença II, 65.075-I20 São Luis,

Maranhão, Brazil

Tel +559832l 44127

Email lets.mg@gmail.com
Objectives: The objectives of this study were to assess the adherence of Streptococcus mutans biofilms grown over conventional ligature (CL) or self-ligating (SL) metal brackets and their bacterial viability after $0.12 \%$ chlorhexidine (CHX) digluconate treatment.

Materials and methods: The sample consisted of 48 metallic orthodontic brackets divided randomly into two groups: CL $(n=24)$ and SL brackets $(n=24)$. S. mutans biofilms were grown over the bracket surface ( $96 \mathrm{~h}$ ) and treated with CHX (positive control) or $0.9 \%$ phosphatebuffered saline (PBS) (negative control) for $1 \mathrm{~min}$ each. Quantitative analysis was assessed by colony-forming units, and fluorescence microscopy was performed aiming to illustrate the outcomes. The tests were done in triplicate at three different times $(n=9)$. Data were analyzed using ANOVA and Tukey test $(P<0.05)$.

Results: There were significant differences in brackets' biofilm formation, being CL largely colonized compared with SL, which was observed by colony-forming unit counting $(P<0.05)$ and microcopy images. Significant reduction in the viability of $S$. mutans was found in both brackets treated with CHX compared to PBS $(P<0.05)$.

Conclusion: The antimicrobial activities of CHX were similar for CL and SL brackets $(P>0.05)$. In conclusion, a lower colonization was achieved in SL brackets and $S$. mutans biofilms were susceptible to CHX treatment to both studied brackets.

Keywords: biofilm, chlorhexidine, orthodontic brackets, Streptococcus mutans

\section{Introduction}

Streptococcus mutans plays a significant role in the cariogenic process, ${ }^{1}$ which is the most prevalent biofilm-associated oral infection in the world, ${ }^{2}$ leading to a significant negative impact on the people's life quality. ${ }^{3}$ The dental plaque accumulation also occurs in orthodontic appliances ${ }^{4}$ due to the establishment of new retention sites around the components (eg, bands, wires, and brackets) modifying the $\mathrm{pH}$ oral environment, increasing the $S$. mutans colonization, and favoring the occurrence of enamel demineralization and biofilm oral diseases. ${ }^{5}$

The diverse morphological characteristics of brackets currently available might directly influence biofilm formation and accumulation as well. ${ }^{1,6,7}$ Among the metallic devices, self-ligating (SL) brackets differ by the use of a metal clip for retaining the orthodontic arch wire instead of elastomeric ligatures used in conventional ligature (CL) brackets. ${ }^{8}$ Some studies show that SL brackets are less susceptible to bacterial colonization due to their shape and the absence of metallic or elastomeric ligatures, ${ }^{5,9,10}$ which is capable of better hygiene promotion. ${ }^{8,11,12}$ Despite these technological advances, the 
problem of biofilm formation over the brackets persists in the daily orthodontic practice. ${ }^{13}$

Many studies describe the efficacy of the mechanical removal of biofilm by brushing and flossing performed by the individual or professional cleaning. ${ }^{1,14,15}$ However, chemical control should be carried out when the mechanical control cannot be performed properly. The literature presents numerous antimicrobial substances for therapeutical or prophylactic chemical control, differing in chemical nature, mechanism of action, clinical presentation, and efficacy. ${ }^{16}$

Chlorhexidine (CHX) digluconate has been proved to be effective ${ }^{16-18}$ and selected as a standard chemical therapeutic agent for that purpose. ${ }^{19,20}$ The mouthwash is a solution containing $0.12 \% \mathrm{CHX}$ gluconate whose active ingredient is hydrosoluble and dissociates quickly at physiological $\mathrm{pH}$, releasing positively charged main substance. The mechanism of action is related to its cationic charge, which links to microbial cell walls and other complex, altering the osmotic balance of the organism, leading to cell death. CHX is an antiseptic used against gram-positive, gram-negative microorganisms and some yeasts. Although there is increasing evidence about the application and use of CHX, there are few studies discussing its use in different designs of orthodontic brackets and comparing chemical antimicrobial action on cariogenic biofilms, useful information for orthodontic community.

Thus, the objectives of this in vitro study were to investigate the bacterial viability of $S$. mutans biofilms formed on CL and SL brackets treated with $0.12 \%$ CHX and compare its formation by fluorescence microscopy (FM) analysis.

\section{Materials and methods}

\section{Sample of orthodontic brackets}

CL orthodontic brackets (Morelli Prescription Roth Light) for lower incisors using elastomeric ligature attached and SL orthodontic brackets (Morelli Prescription Roth SLI) for lower incisors were used in the present study.

\section{Microbiological samples}

A standard suspension of $S$. mutans UA159 was inoculated in brain heart infusion broth with $1 \%$ glucose and incubated for $18 \mathrm{~h}$ at $37^{\circ} \mathrm{C}$ under microaerophilic condition $\left(5 \%\right.$ of $\left.\mathrm{CO}_{2}\right)$. This bacterial culture was then centrifuged at $3,000 \mathrm{rpm}$ for $5 \mathrm{~min}$, and the supernatant was discarded. Then, the cell pellet was resuspended in $5 \mathrm{~mL}$ of sterile solution of $0.9 \%$ sodium chloride $(\mathrm{NaCl})$. The cell numbers were measured by means of a spectrophotometer (wavelength at $540 \mathrm{~nm}$ at a concentration of $1 \times 10^{6}$ cells $\left./ \mathrm{mL}\right)$.

\section{Experimental situation}

CHX digluconate at $0.12 \%$ mouthwash (PerioGard; ColgatePalmolive, Sao Paulo, Brazil) was used for testing the $S$. mutans biofilms over two different types of metal brackets. Forty-eight orthodontic brackets were divided randomly into CL brackets $(n=24)$ with elastomeric ligation attached and SL brackets ( $\mathrm{n}=24)$ treated with CHX immersion for $1 \mathrm{~min}$ (test group) and $0.9 \%$ phosphate-buffered saline (PBS) for $1 \mathrm{~min}$ (control group). The tests were performed in triplicate in three different times.

\section{In vitro biofilm formation}

Sterilized brackets were transferred into a 24-well plate and incubated with $1,000 \mu \mathrm{L}$ microorganism suspension brain heart infusion with $1 \%$ glucose at a concentration of $1 \times 10^{6}$ cells $/ \mathrm{mL}$, and the plates were incubated anaerobically at $37^{\circ} \mathrm{C}$ as a static culture for $24 \mathrm{~h}$ for biofilm formation. ${ }^{21}$ Biofilm maturation was performed with a medium change daily during $96 \mathrm{~h}$.

\section{Counting colony-forming units (CFUs)}

After treatment with CHX and PBS, the brackets were solubilized in a Falcon tube with $5 \mathrm{~mL}$ of PBS for the analysis of microorganisms. Aliquots of suspensions after treatments were used to perform 10-fold serial dilutions, and the diluted samples were plated onto 5\% defibrinated sheep blood agar (Sigma-Aldrich Co., St Louis, MO, USA) and then incubated at $37^{\circ} \mathrm{C}, 5 \% \mathrm{CO}_{2}$ for $48 \mathrm{~h}$ to investigate the number of viable microorganisms. After incubation, the total number of CFUs was determined, and the number of CFUs per millimeter of suspension $(\mathrm{CFU} / \mathrm{mL})$ was obtained and transformed into logarithm $\left(\log _{10}\right)$.

\section{Fluorescence microscopy}

For FM analysis, the viability of bacteria within the brackets' biofilms of each group was determined by staining the biofilms with LIVE/DEAD BacLight Bacterial Viability Kit (Molecular Probes Inc., Eugene, OR, USA), which includes two fluorescent nucleic acid stains: green-SYTO 9 and redpropidium iodide. The biofilms were treated according to the manufacturer's instructions, being stained immediately after the treatments, kept in the dark, and protected from light for $20 \mathrm{~min}$ at $35^{\circ} \mathrm{C}$ for analysis. Stained biofilms were examined under a fluorescence microscope (Axio Imager Z2; Carl Zeiss Meditec AG, Jena, Germany) using specific filters, $488 / 507 \mathrm{~nm}$ for the detection of SYTO 9 and 503/615 nm 
for the detection of propidium iodide and examined at $63.4 \times$ magnification.

\section{Statistical analysis}

The assays were performed in triplicate for each group, and the procedure was repeated three times on different days $(n=9)$. The mean and the SD of the numbers of CFU for each treatment were calculated. CFUs were transformed into logarithmical scale $\left(\log _{10}\right)$ in order to reduce variance heterogeneity. A two-way analysis of variance test followed by Tukey test was used to verify the differences among all the studied groups. The cutoff level of significance was set at $5 \%$.

\section{Results}

\section{Quantitative analysis}

Both brackets' groups treated with $\mathrm{CHX}$ demonstrated a significant statistical difference $(P>0.05)$ in comparison to PBS treatment to $S$. mutans viability but with no significant statistical differences among the SL and CL brackets treated with $\mathrm{CHX}(P<0.05)$ (Figure 1).

\section{Qualitative analysis}

FM images showed more red cells to both group brackets treated with $\mathrm{CHX}$ indicating the antimicrobial effect (Figure 2B and 2D) when compared with the brackets treated with PBS (Figure 2A and 2C).

\section{Discussion}

Orthodontic treatment for functional rehabilitation and facial esthetic is often necessary due to the high prevalence of malocclusion. ${ }^{22,23}$ However, patients undergoing fixed orthodontic therapy experience ecological changes, which can decrease the oral health conditions. ${ }^{4,18}$ Brackets create many areas that harbor dental biofilms and make much harder to clean teeth adequately. The acids produced by the bacteria within are able to cause white spot lesion, areas of demineralized enamel surrounding the brackets. In the case of continuous acid challenges, it may lead to progress into dental caries cavity.

In some clinical cases, white spot lesions are considered as undesired side effects of orthodontic treatment. Considering that part of the population is undergoing orthodontic treatment, ${ }^{23,24}$ efforts for clinical excellence and prevention should be kept in mind when this kind of treatment is needed. ${ }^{13}$

This study aimed to evaluate the following two types of metal orthodontic brackets, widely used around the world:8,24 CL, which has consolidated its use, and SL, which shows a trend among clinical orthodontists seeking to offer an optimized treatment. ${ }^{12}$

The orthodontic patient usually presents some difficulties to perform a correct hygiene, causing a greater accumulation of biofilms and qualitative changes in the local flora. ${ }^{4,5,25}$ There is no consensus regarding the adherence of $S$. mutans in brackets. Some authors have attested more adherences to brackets with

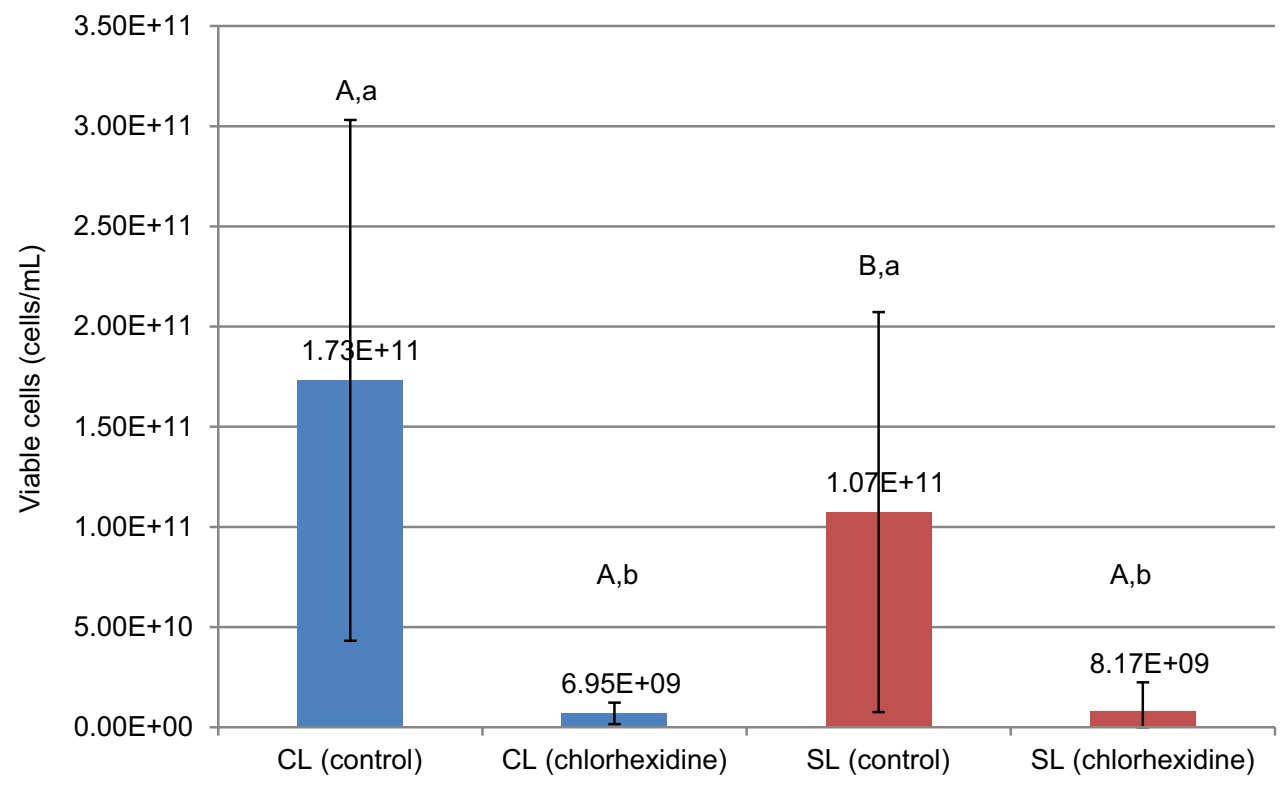

Figure I Viable cells after treatment in CL or SL.

Notes: $A$ and $B$ indicate significant differences between the brackets. a and $b$ indicate significant differences between treatments (ANOVA, Tukey $P<0.05$ ). Abbreviations: $\mathrm{CL}$, conventional ligature; SL, self-ligating. 

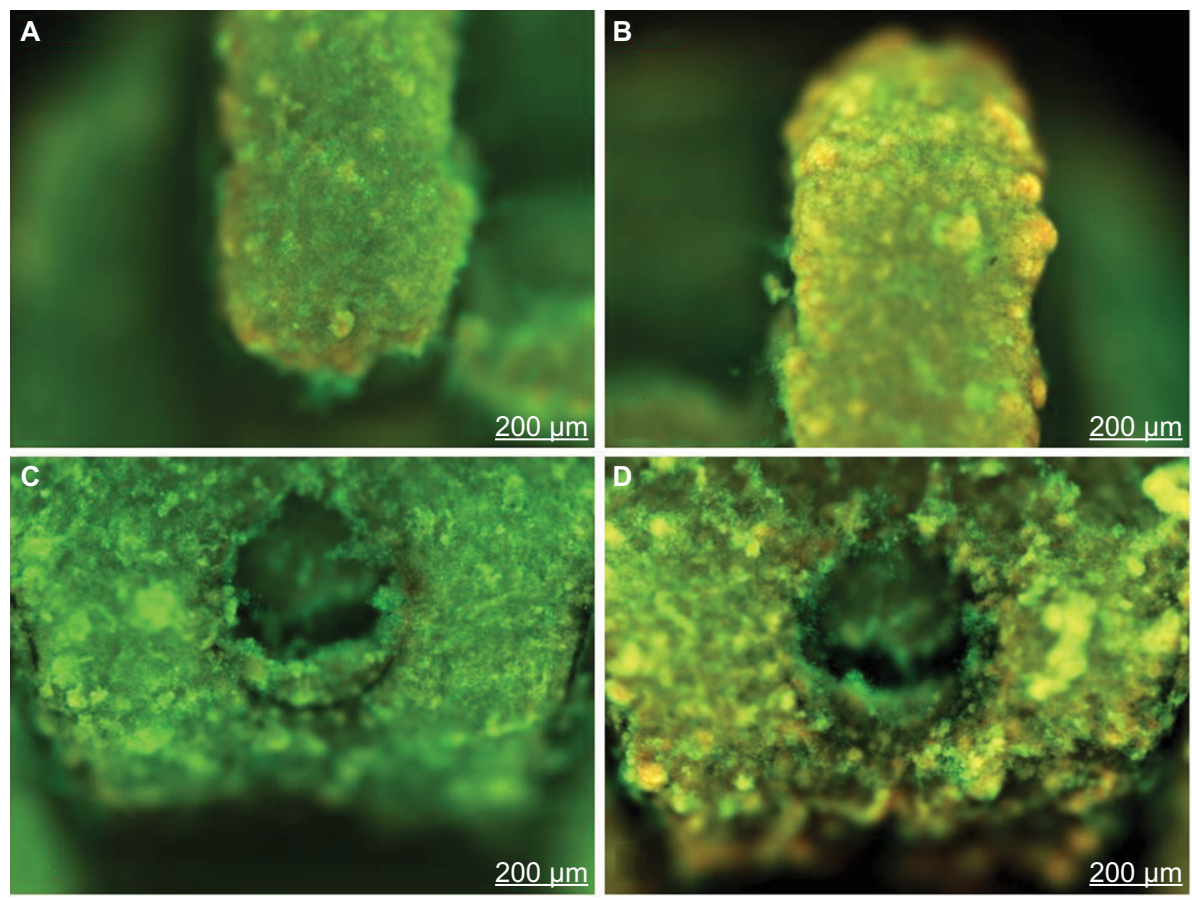

Figure 2 Viable cells after treatments in $C L$ or SL brackets.

Notes: (A) CL after PBS. (B) CL after CHX. (C) SL after PBS. (D) SL after CHX. Abbreviations: $\mathrm{CHX}$, chlorhexidine; $\mathrm{CL}$, conventional ligature; $\mathrm{SL}$, self-ligating.

elastomeric ligatures, ${ }^{8,26}$ whereas other studies have shown higher accumulation on SL brackets. However, other investigations have reached no differences related to this issue. ${ }^{25,27,28}$

The present study found differences in the number of S. mutans colonies between both groups of brackets in which CL showed more accumulation of bacteria. Some studies show that the SL brackets present better hygiene, ${ }^{8,11}$ and they are less susceptible to bacterial colonization due to their shape and lack of wire or elastomeric ligatures. ${ }^{12}$

The following two investigative methods were used to investigate the biofilm formation on different types of brackets studied: first, a quantitative analysis that was able to detect cell viability of the biofilms on orthodontic brackets and a comparative analysis between SL and CL adhesion of S. mutans and, second, FM, an imaging technique used to study the dynamics of living and dead cells, had proven that CHX decreased the amount of living bacteria on the surface of the studied brackets. Thus, the outcomes indicated that CHX presented an inhibitory effect on S. mutans biofilms in both SL and CL brackets, indicating the benefits of this prescription (eg, mouthwash) as an adjuvant for biofilm control in patients who are under orthodontic treatment. Despite literature recommendation that indicates the continuous use of CHX as mouthwash for standard chemical control, ${ }^{29}$ it is worth pointing out that the long-term use stains teeth and tongue, besides affect the taste sensation.

The selection of $S$. mutans as microorganism test was based on its importance in the etiology of dental caries, ${ }^{1}$ due to several factors of virulence, as acidogenesis, high adaptability to environment, the presence of cell surface adhesins, and production of extracellular polysaccharides. ${ }^{1,4,6}$ The monospecies biofilm model was used to evaluate the antimicrobial effect of CHX on orthodontic brackets studied. This method presents a limitation, such as absence of conditions that simulate those found in the oral cavity (eg, presence of saliva, oral $\mathrm{pH}$, and other microorganisms $\mathrm{s}^{30}$ ).

Presently, metallic brackets are the most widely used ${ }^{31,32}$ regardless of model or prescription. Although the concept does not characterize a novelty in orthodontics, the SL system was widespread in the early 21 st century ${ }^{11,31}$ by stating the low friction as differential, which facilitates the start of tooth movement by decreasing the initial resistance to movement. This has aroused great interest among orthodontists, since the reduction in friction levels during orthodontic treatment promises faster treatment and less number of dental appointments.

The chair saving time ${ }^{12}$ and slightly lower incisor proclination $^{32}$ appear to be the only significant advantages of SL systems compared with CL systems. The choice of the bracket system and its prescription should be guided by the judgment of professional, permeated by their clinical experience and an individualized diagnosis. This decision should include biological and biomechanical concepts and be supported by 
scientific evidence. Furthermore, apart from the model of bracket prescription, the role of orthodontist is to properly inform this special population the potential risks of treatment and to emphasize caries control programs, especially the importance of the correct oral hygiene.

Other studies changing the exposure time to CHX and comparing different therapies and other chemical agents may be desirable. Additionally, it is inferred that this study model can be effectively used to assess orthodontic brackets of different compositions, comparison of commercial brands, as well as studying the action of other antimicrobial agents in the future.

\section{Conclusion}

The present study supports that in both brackets treated with CHX, a significant reduction in the viability of $S$. mutans was found compared to control treatment, indicating the antimicrobial activities of CHX for SL and CL brackets. When comparing CFU counting between groups, there was a significant difference in the number of $S$. mutans colonies, where SL group had lower scores than the CL group, highlighting an SL clinical advantage over CL related to the adhesion of cariogenic biofilms. More evidence and clinical trials are necessary to support the reached outcomes.

\section{Disclosure}

The authors report no conflicts of interest in this work.

\section{References}

1. Loe H, Theilade E, Jensen SB. Experimental gingivitis in man. J Periodontol. 1965;36:177-187.

2. Petersen PE, Bourgeois D, Ogawa H, Estupinan-Day S, Ndaye C. The global burden of oral diseases and risk to oral health. In: Organization WH, editor. Bull. Geneva: World Health Organization; 2005:661-669.

3. Bagramian RA, Garcia-Godoy F, Volpe AR. The global increase in dental caries. A pending public health crisis. Am J Dent. 2009;22(1):3-8.

4. Rego RO, Oliveira CA, dos Santos-Pinto A, et al. Clinical and microbiological studies of children and adolescents receiving orthodontic treatment. Am J Dent. 2010;23(6):317-323.

5. Rosenbloom RG, Tinanoff N. Salivary Streptococcus mutans levels in patients before, during, and after orthodontic treatment. Am J Orthod Dentofacial Orthop. 1991;100(1):35-37.

6. Theilade E. The experimental gingivitis studies: the microbiological perspective. J Dent Res. 1996;75(7):1434-1438.

7. Shelley WB. Gingival hyperplasia from dental braces. Cutis. 1981;28(2):149-150.

8. Shivapuja PK, Berger J. A comparative study of conventional ligation and self-ligation bracket systems. Am J Orthod Dentofacial Orthop. 1994;106(5):472-480.

9. Balenseifen JW, Madonia JV. Study of dental plaque in orthodontic patients. J Dent Res. 1970;49(2):320-324.

10. Forsberg CM, Brattstrom V, Malmberg E, Nord CE. Ligature wires and elastomeric rings: two methods of ligation, and their association with microbial colonization of Streptococcus mutans and lactobacilli. Eur J Orthod. 1991;13(5):416-420.
11. Damon DH. The rationale, evolution and clinical application of the self-ligating bracket. Clin Orthod Res. 1998;1(1):52-61.

12. Paduano S, Cioffi I, Iodice G, Rapuano A, Silva R. Time efficiency of self-ligating vs conventional brackets in orthodontics: effect of appliances and ligating systems. Prog Orthod. 2008;9(2):74-80.

13. Enaia M, Bock N, Ruf S. White-spot lesions during multibracket appliance treatment: a challenge for clinical excellence. Am J Orthod Dentofacial Orthop. 2011;140(1):e17-e24.

14. Vermaire JH, van Loveren C, Brouwer WB, Krol M. Value for money: economic evaluation of two different caries prevention programmes compared with standard care in a randomized controlled trial. Caries Res. 2014;48(3):244-253.

15. Costa MR, Silva VC, Miqui MN, Sakima T, Spolidorio DM, Cirelli JA. Efficacy of ultrasonic, electric and manual toothbrushes in patients with fixed orthodontic appliances. Angle Orthod. 2007;77(2):361-366.

16. Kocak MM, Ozcan S, Kocak S, Topuz O, Erten H. Comparison of the efficacy of three different mouthrinse solutions in decreasing the level of Streptococcus mutans in saliva. Eur J Dent. 2009;3(1):57-61.

17. Ullsfoss BN, Ogaard B, Arends J, Ruben J, Rolla G, Afseth J. Effect of a combined chlorhexidine and NaF mouthrinse: an in vivo human caries model study. Scand J Dent Res. 1994;102(2):109-112.

18. Lundstrom F, Krasse B. Caries incidence in orthodontic patients with high levels of Streptococcus mutans. Eur J Orthod. 1987;9(2):117-121.

19. Pan PC, Harper S, Ricci-Nittel D, Lux R, Shi W. In-vitro evidence for efficacy of antimicrobial mouthrinses. J Dent. 2010;38(Suppl 1):S16-S20.

20. Lakade LS, Shah P, Shirol D. Comparison of antimicrobial efficacy of chlorhexidine and combination mouth rinse in reducing the Mutans streptococcus count in plaque. J Indian Soc Pedod Prev Dent. 2014;32(2):91-96.

21. Duarte S, Klein MI, Aires CP, Cury JA, Bowen WH, Koo H. Influences of starch and sucrose on Streptococcus mutans biofilms. Oral Microbiol Immunol. 2008;23(3):206-212.

22. Angle EH. Classification of malocclusion. Dent Cosmos. 1899;41(3):16.

23. Petrovic D, Vukic-Culafic B, Ivic S, Djuric M, Milekic B. Study of the risk factors associated with the development of malocclusion. Vojnosanit Pregl. 2013;70(9):817-823.

24. Ren Y, Jongsma MA, Mei L, van der Mei HC, Busscher HJ. Orthodontic treatment with fixed appliances and biofilm formation: a potential public health threat? Clin Oral Investig. 2014;18(7):1711-1718.

25. Pejda S, Varga ML, Milosevic SA, et al. Clinical and microbiological parameters in patients with self-ligating and conventional brackets during early phase of orthodontic treatment. Angle Orthod. 2013;83(1):133-139.

26. Pellegrini P, Sauerwein R, Finlayson T, et al. Plaque retention by selfligating vs elastomeric orthodontic brackets: quantitative comparison of oral bacteria and detection with adenosine triphosphate-driven bioluminescence. Am J Orthod Dentofacial Orthop. 2009;135(4):426. e1-e9. Discussion-7.

27. Pandis N, Papaioannou W, Kontou E, Nakou M, Makou M, Eliades T. Salivary Streptococcus mutans levels in patients with conventional and self-ligating brackets. Eur J Orthod. 2010;32(1):94-99.

28. Buck T, Pellegrini P, Sauerwein R, et al. Elastomeric-ligated vs selfligating appliances: a pilot study examining microbial colonization and white spot lesion formation after 1 year of orthodontic treatment. Orthodontics. 2011;12(2):108-121.

29. Greenstein G, Berman C, Jaffin R. Chlorhexidine. An adjunct to periodontal therapy. J Periodontol. 1986;57(6):370-377.

30. Eliades T, Eliades G, Brantley WA. Microbial attachment on orthodontic appliances: I. Wettability and early pellicle formation on bracket materials. Am J Orthod Dentofacial Orthop. 1995;108(4):351-360.

31. Castro RM, Neto PS, Horta MC, Pithon MM, Oliveira DD. Comparison of static friction with self-ligating, modified slot design and conventional brackets. J Appl Oral Sci. 2013;21(4):314-319.

32. Pandis N, Polychronopoulou A, Eliades T. Self-ligating vs conventional brackets in the treatment of mandibular crowding: a prospective clinical trial of treatment duration and dental effects. Am J Orthod Dentofacial Orthop. 2007;132(2):208-215. 


\section{Publish your work in this journal}

Clinical, Cosmetic and Investigational Dentistry is an international, peer-reviewed, open access, online journal focusing on the latest clinical and experimental research in dentistry with specific emphasis on cosmetic interventions. Innovative developments in dental materials, techniques and devices that improve outcomes and patient satisfac- tion and preference will be highlighted. The manuscript management system is completely online and includes a very quick and fair peerreview system, which is all easy to use. Visit http://www.dovepress. com/testimonials.php to read real quotes from published authors.

Submit your manuscript here: https://www.dovepress.com/clinical-cosmetic-and-investigational-dentistry-journal 